\title{
A strategy disruption component to retrieval-induced forgetting
}

\author{
MICHAEL D. DODD \\ University of Toronto, Toronto, Ontario, Canada \\ ALAN D. CASTEL \\ Washington University, St. Louis, Missouri \\ and University of Toronto, Toronto, Ontario, Canada \\ and \\ KAREN E. ROBERTS \\ University of Toronto, Toronto, Ontario, Canada
}

\begin{abstract}
Retrieval-induced forgetting refers to a paradoxical occurrence wherein the act of remembering some material disrupts the retrieval of other, related material (see, e.g., M. C. Anderson, R. A. Bjork, \& E. L. Bjork, 1994). This effect is generally accounted for in terms of inhibitory processes. Across three experiments, we test the inhibitory account of retrieval-induced forgetting, as well as whether there may be a strategy disruption component to the effect. In our first two experiments, we manipulate which items individuals are cued to recall during retrieval practice and demonstrate that retrievalinduced forgetting can be neutralized when those items do not interfere with the individual's retrieval strategy. In the third experiment, we confirm this finding with a different set of stimuli. These results are inconsistent with a purely inhibitory account of retrieval-induced forgetting, and we discuss implications for inhibition theory and strategy disruption in light of these and other findings.
\end{abstract}

Over the past decade, there has been increased interest in the role of inhibition in memory. Indeed, a variety of memory phenomena (e.g., directed forgetting) are speculated to be the result of inhibitory processes (see C. M. MacLeod, Dodd, Sheard, Wilson, \& Bibi, 2003). A recent example of such a phenomenon is retrieval-induced forgetting - a paradoxical occurrence wherein the act of remembering some material disrupts the retrieval of other, related material (see, e.g., M. C. Anderson, R. A. Bjork, \& E. L. Bjork, 1994; M. D. MacLeod \& Macrae, 2001). Given the current interest in retrieval-induced forgetting, the development of theories to explain this phenomenon has become central in the field of memory research.

Retrieval-induced forgetting effects have been observed repeatedly by M. C. Anderson and colleagues (see, e.g., M. C. Anderson et al., 1994; M. C. Anderson, E. L. Bjork, \& R. A. Bjork, 2000; M. C. Anderson, Green, \& McCulloch, 2000). Although these researchers coined the phrase retrieval-induced forgetting, similar findings had been reported in the early 1970 s and 1980 s by a number of researchers (e.g., Blaxton \& Neely, 1983; Roediger

This research was supported by Natural Sciences and Engineering Research Council (NSERC) of Canada postgraduate scholarships to M.D.D. and A.D.C. We thank Colin MacLeod for providing valuable methodological insight and Karl-Heinz Bäuml, Michael Anderson, Norman Farb, and an anonymous reviewer for helpful comments on earlier drafts of the manuscript. Correspondence should be addressed to M. D. Dodd, Department of Psychology, University of British Columbia, 2136 West Mall, Vancouver, BC, V6T 1Z4 Canada (e-mail: mike@psych.ubc.ca).
\& Schmidt, 1980; A. D. Smith, 1971). M. C. Anderson et al. (1994) first observed retrieval-induced forgetting by having participants study lists of words, with each list containing various category-exemplar pairs (e.g., FruitOrange, Drink-Vodka). A number of different exemplars were used for each category (e.g., Fruit-Banana, FruitOrange, Fruit-Lemon; six exemplars total for each of 10 categories), and participants were told to learn these pairings for a later memory test. After the study session, participants completed a practice session in which they were given category names and word stems (e.g., Fruit-Or__ for half of the words from half of the categories, and then they were instructed to complete the stems with words from the studied lists. Each of these stems was completed multiple times, so that the participants had a good deal of retrieval practice with these items. Following a 20 -min retention interval, participants were provided with category cues and asked to recall all of the previously presented words from these categories. Not surprisingly, recall was best for the practiced items from practiced categories $(\mathrm{Rp}+)$. Interestingly, though, recall was poorer for unpracticed items from practiced categories $(\mathrm{Rp}-)$ than for (unpracticed) items from entirely unpracticed categories (Np). M. C. Anderson et al. (1994) argued that this detriment was indicative of inhibitory processes that suppress related material when practiced material is correctly recalled. Under their account, during the practice session, studied words compete with each other during a search for the correct stem completion. This competition necessitates a suppression or inhibition of competing words, 
which in turn makes them less accessible at a later time. More specifically, though, M. C. Anderson et al. reported that retrieval impairment occurred for strong categorical exemplars (e.g., Fruit-Orange) but not for weak categorical exemplars (e.g., Tree-Hickory). They hypothesized that strong categorical exemplars are more likely to interfere during retrieval practice because of their greater associative strength, which causes them to require more inhibition. Weak categorical exemplars are less likely to interfere and may not need to be inhibited during practice. This idea is similar to the idea of "reactive inhibition," in which inhibition is greater to the extent that a distractor might be expected to intrude (see Houghton \& Tipper, 1994; Wundt, 1902).

The finding that strong exemplars were more impaired than weak exemplars seemed to suggest that these "inhibitory processes" were quite specific in nature. The replicability of this effect, however, has been called into question, with some researchers providing evidence that only strong items are suppressed during practice (see, e.g., Bäuml, 1998), whereas others have failed to find any differential effect of retrieval-induced forgetting as a function of exemplar type (see, e.g., Williams \& Zacks, 2001). In the interim, however, a number of other findings have been reported that further strengthen the notion that retrieval-induced forgetting is attributable to inhibition. For example, M. C. Anderson and colleagues (M. C. Anderson \& Bell, 2001; M. C. Anderson \& Spellman, 1995) have demonstrated that retrieval-induced forgetting is cue independent, meaning that a decrement for unpracticed words from practiced lists is observed even when the original retrieval practice cue is not employed at test (e.g., if the category-exemplar pair Fruit-Banana was impaired during practice, then the exemplar "Banana" is later impaired when participants are tested with the retrieval cue MonkeyB__; M. C. Anderson, 2003). This finding seems quite consistent with the notion that unpracticed items are inhibited, making them less accessible at a later time. Retrieval-induced forgetting has also been observed in tests of implicit memory (see, e.g., Perfect, Moulin, Conway, \& Perry, 2002; Veling \& van Knippenberg, 2004), and this fact seems indicative of a role for inhibitory processes. Moreover, a number of researchers have provided evidence for a greater generality of the effect, extending it to the realms of social cognition (see, e.g., M. D. MacLeod \& Macrae, 2001; Macrae \& MacLeod, 1999), eyewitness memory (see, e.g., Shaw, Bjork, \& Handal, 1995), and perception (see, e.g., Ciranni \& Shimamura, 1999). For example, M. D. MacLeod and Macrae had participants form an impression of two individuals (John and Bill), each of whom was described via a list of 10 traits. In this situation, there were no "strong" or "weak" exemplars, because the target individuals were unknown to participants prior to the study. Following a practice session in which individuals were cued to recall half of the traits describing one of the individuals, retrieval-induced forgetting was observed on a final recall test for these traits.

Although inhibitory-based explanations of retrievalinduced forgetting have received a great deal of support in the last few years, the results from M. D. MacLeod and Macrae (2001) and Williams and Zacks (2001) present some challenges to this explanation. That retrievalinduced forgetting is observed independent of item strength is inconsistent with the initial inhibitory account, which centered on inhibitory processes that act on competing responses during the practice session (M. C. Anderson \& Spellman, 1995). This is somewhat surprising, given that M. C. Anderson et al. (1994) initially argued that retrieval-induced forgetting would be more prevalent for strong exemplars during recall, since these items would have required more inhibition during practice to prevent response competition (with the greater inhibition placed on these items during practice leading to a greater impairment of recall during the final memory test). Nonetheless, the inhibition account of retrieval-induced forgetting has endured, albeit in more general terms: Retrieving any list item during practice is now thought to lead to a suppression or inhibition of other list items, thus accounting for the later detriment in recalling these words relative to words from the unpracticed list.

There is, however, a related phenomenon known as part-list cuing, which has been previously accounted for in terms of inhibitory processes: Presenting a subset of the to-be-remembered items at retrieval to "aid" recall actually reduces the proportion of correctly recalled words from the rest of the list in comparison with when the subset is not presented (see, e.g., Basden, Basden, \& Galloway, 1977; Slamecka, 1968; Todres \& Watkins, 1981). Part-list cuing effects were initially reported by Slamecka $(1968,1969)$, and since this seminal work, a number of researchers have examined both the facilitatory and inhibitory effects of presenting a subset of studied words as cues during recall (see, e.g., Basden et al., 1977; Penney, 1988; Roediger, 1974; Sloman, Bower, \& Rohrer, 1991; Todres \& Watkins, 1981).

Although part-list cuing and retrieval-induced forgetting appear to be separable effects, the parallels between them deserve mention, because part-list cuing has been accounted for in terms of inhibitory processes, analogous to the manner in which M. C. Anderson and colleagues currently account for retrieval-induced forgetting. With regard to part-list cuing, it was posited that presenting the cue list led to a strengthening in memory of these cued items and a blocking (inhibition) of the remainder of the to-be-recalled words (Basden et al., 1977). The inhibition account of part-list cuing effects posits that the cues are used to recall a certain number of category exemplars, thus strengthening the memory trace for these items and inhibiting the memory trace for other, related category exemplars. In Basden's words, "cuing may facilitate category recall but usually inhibits instance recall" (Basden et al., 1977, p. 100).

Basden et al. (1977), however, conducted a study to examine the inhibition explanation of part-list cuing and concluded that their results could not be accounted for adequately using inhibition theory. ${ }^{1}$ Instead, Basden et al. (1977; see also Basden \& Basden, 1995) put forth a strategy disruption account for the effects of part-list cuing: 
"Editing cue words from recall disrupts that recall, perhaps by forcing a recall order inconsistent with intracategory organization" (p. 107). Although the plausibility of this strategy disruption hypothesis has been debated (see, e.g., Peynircioğlu, 1989), this account has endured and is now considered a viable alternative to the inhibition view.

That part-list cuing can be accounted for without inhibitory processes leads to the question of whether retrievalinduced forgetting can be accounted for in a similar fashion. Given that the two findings are very similar, it would be parsimonious if both could be accounted for in a similar or identical manner. It could be that the practice session - which generally requires participants to recall a subset of words from one of the lists - disrupts the original organization of studied words in memory, making the unpracticed words from the practiced list less accessible. Words from the unpracticed list, however, are more accessible, because the organization of these items in memory has not been disrupted by the practice session. A number of findings from the literature could be perceived as consistent with this view: Although M. C. Anderson et al. (1994) observed a retrieval-induced forgetting effect up to $20 \mathrm{~min}$ after the practice session, no such effect was observed $24 \mathrm{~h}$ after the practice session (see M. D. MacLeod \& Macrae, 2001). This pattern could be indicative of participants having been far enough removed from the disruptive practice session that they were able to return to their original memory strategies and organization (though it must be noted that this finding is also quite consistent with an inhibitory theory of retrieval-induced forgetting, with the influence of inhibition decreasing over time). M. C. Anderson and McCulloch (1999) reported that individuals are immune to retrieval-induced forgetting when they make multiple connections between list items at study. Thus, even if the practice session disrupts the organization of some items in memory, the durable memory trace afforded by multiple connections should be strong enough to ward off this disruption. (Alternatively, the multiple connections may lead individuals to spontaneously think about other unpracticed list words during the practice session, thus strengthening the memory trace for these items, rather than reducing it.) A similar finding was reported by R. E. Smith and Hunt (2000), who demonstrated that the effects of retrieval-induced forgetting could be reduced when individuals were encouraged to engage in additional "distinctive" processing for each presented word, presumably leading to additional memory traces for these words that were independent of the other list words (e.g., thinking of how each word was different from the previous words). In addition, Williams and Zacks (2001) have argued that their failure to find differential effects of strong as opposed to weak exemplars on retrieval-induced forgetting is contrary to the inhibition account put forth by M. C. Anderson and colleagues, and they therefore argued in favor of a retrieval interference mechanism. According to the retrieval interference account, the strengthening of $\mathrm{Rp}+$ items during the practice session decreases the accessibility of Rp - items because the retrieval mechanism is disrupted by the cued recall of
$\mathrm{Rp}+$ items. This account is very similar to the strategy disruption account outlined here.

It is apparent, then, that at least some of the retrievalinduced forgetting literature can be interpreted as being consistent with strategy disruption rather than with a strictly inhibitory account. In fact, M. C. Anderson et al. (1994) made mention of the relation between part-list cuing and retrieval-induced forgetting in their seminal paper. Subsequent work by M. C. Anderson and colleagues (see, e.g., M. C. Anderson, E. L. Bjork, \& R. A. Bjork, 2000; M. C. Anderson \& McCulloch, 1999) has also made mention of the strategy disruption account, although, in the same context, it has been argued that strategy disruption is not a viable explanation of the existing retrieval-induced forgetting data (see, e.g., M. C. Anderson \& McCulloch, 1999). This argument has been made post hoc, however, in the absence of any explicit test of the strategy disruption account (e.g., "although the present studies were not designed to test the strategy disruption hypothesis, one can imagine how such dynamics might have influenced our results"; M. C. Anderson \& McCulloch, 1999, p. 625). Given that the possible contributions of strategy disruption to retrieval-induced forgetting have not been assessed empirically, the purpose of the present study is to determine whether there is any evidence for a role of strategy disruption in the effect. In our first experiment, we manipulated which items were recalled during the practice session by having participants practice items that were likely, or unlikely, to disrupt their retrieval strategy. The current inhibitory account of retrieval-induced forgetting posits that practicing any subset of items from a studied list should lead to a suppression or inhibition of other items from that list.

\section{EXPERIMENT 1}

In order to examine the locus of retrieval-induced forgetting, we carried out an experiment that allowed for the analysis of retrieval dynamics that might lead to the phenomenon in question. Experiment 1 was a replication and extension of M. D. MacLeod and Macrae's Experiment 1 (2001), in which participants studied traits describing one of two individuals and were asked to form an impression of each. We chose to use the M. D. MacLeod and Macrae paradigm because we wanted a situation in which participants had no preexisting associations between the to-be-studied categories (the target individuals) and the exemplars (the personality traits that described the target individuals). To determine whether strategy disruption can account for retrievalinduced forgetting, however, we employed three retrieval practice manipulations. If retrieval-induced forgetting is attributable to inhibitory processes, then practicing any subset of items from a list should lead to a reduction in memory for the other items from that list. If, however, there is a strategy disruption component to retrievalinduced forgetting, we should be able to neutralize this disruption by cuing individuals to recall items in an order that is roughly consistent with their retrieval strategy. In 
the random practice condition, participants were cued to recall a random subset of the studied items describing one of the individuals. This condition was a basic replication of M. D. MacLeod and Macrae (Experiment 1) and is consistent with the manner in which retrieval practice is usually conducted in this paradigm (see, e.g., M. C. Anderson, E. L. Bjork, \& R. A. Bjork, 2000; M. C. Anderson et al., 1994). The other two retrieval practice manipulations, however, were novel and were developed for the present experiment to create a situation in which the retrieval practice session was unlikely to disrupt retrieval strategy. In the serial position practice condition, participants were cued to recall the last five traits they studied that described 1 of the 2 individuals. Assuming that participants memorize traits serially (and tend to recall items in the same order in which they have been presented; see Reysen \& Nairne, 2002, for a review), forcing them to recall the latter half of a list should leave primacy intact. Hence, the unpracticed items from the practiced category should still be highly accessible. In the every-other-word practice condition, participants were cued to recall every other item from one of the studied lists. Reysen and Nairne (2002) examined the effects of part-set cuing on veridical and false recall and speculated that presenting every other word to participants as part-list cues would facilitate recall, rather than reducing it. Their prediction was not entirely substantiated, because every-other-word partlist cues led to a significant reduction in both veridical and false recall when compared with free recall (though it should be noted that the effect of part-list cuing was less disruptive in the every-other-word condition than in the random-cued condition for veridical recall). Regardless, the prediction that less disruptive retrieval cues should facilitate recall has been supported by numerous researchers (e.g., Basden \& Basden, 1995; Sloman et al., 1991) and therefore, we include it as a retrieval practice condition here. Again, being cued to recall every other studied item should be consistent with most participants' retrieval strategies and, therefore, the unpracticed items for the practiced category should still be highly accessible at recall. If retrieval-induced forgetting is attributable to inhibition, then we should expect to observe retrieval-induced forgetting in all three of our practice conditions, because practicing any subset of studied items should lead to the inhibition of related, unstudied items. If, however, there is a strategy disruption component to retrieval-induced forgetting, we should observe the effect only in the random practice condition. The other two conditions should be resistant to retrieval-induced forgetting, because during retrieval practice, individuals are cued to recall items in an order that is roughly consistent with their retrieval strategy.

\section{Method}

Participants. Seventy-two students from the University of Toronto at Scarborough took part individually in a 30-min session, and received bonus course credit for their participation.

Design and Experimental Control. The experiment had a $3 \times$ 3 mixed design, with item type ( $\mathrm{Rp}+, \mathrm{Rp}-$, or $\mathrm{Np})$ as the within- subjects factor and rehearsal group (serial position, every other word, or random) as the between-subjects factor. Of the 72 participants, 24 were randomly assigned to each experimental condition.

Apparatus and Procedure. Experimental programs were written in QuickBASIC Version 4.5. An IBM-compatible 486 computer displayed the stimuli on a Magnavox 15-in. color monitor.

The experimental materials were derived from M. D. MacLeod and Macrae (2001) and consisted of two trait sets that these researchers had "matched for word length, word frequency (Francis \& Kučera, 1982), and valence (N. H. Anderson, 1968)" (M. D. MacLeod \& Macrae, 2001, p. 149). Each trait set was divided into two subgroups to create a practiced (i.e., $\mathrm{Rp}+$ ) and an unpracticed (i.e., $\mathrm{Rp}-$ ) group of items for each participant. The traits in Set 1 were trustful, sensible, cultured, romantic, studious, and pleasant, spirited, vigorous, rational, sociable. The traits in Set 2 were cheerful, tolerant, creative, outgoing, discreet, and educated, talented, generous, skillful, artistic.

The procedure was similar to that employed by M. D. MacLeod and Macrae (2001), the exception being the manipulation of practiced items. The participants sat about $50 \mathrm{~cm}$ from the monitor. They were told that they would be learning about two individuals (John and Bill), and they were asked to form an impression of each and to memorize the traits that described them for a later memory test. During the study phase, the participants were shown name-trait pairs (e.g., Bill-Outgoing). There were 10 traits that described John and 10 that described Bill. The two lists of traits were presented in a blocked fashion, and each individual trait was presented for $5 \mathrm{sec}$. The order of presentation of the names (John and Bill) was counterbalanced, and the presentation of the traits was randomized with the following restrictions: For the serial position practice group, the items within each subgroup were randomized, but the first 5 traits presented were all from the same subgroup and the second 5 traits were all from the other subgroup within the same set (e.g., Items $6,7,8,9$, and 10 were all from the same subgroup). For the everyother-word practice group, the items within each subgroup were randomized, and traits were presented by alternating between each group (e.g., Items 1, 3, 5, 7, and 9 were all from the same subgroup). For the random practice condition, all items were randomized.

Immediately following the study phase, the participants completed a retrieval practice phase in which they received a test booklet that probed their memory, via cued recall, for half of the traits that described one of the individuals. Each page of the booklet contained a name and the first two letters of one of the traits they had studied that described that individual (e.g., Bill-Ou___ participants were asked to write down the studied trait that completed the word stem. Each item in the practice phase was presented three times, for a total of 15 retrieval practice trials. All items were counterbalanced so that each item appeared an equal number of times in each condition $(\mathrm{Rp}+, \mathrm{Rp}-$, and $\mathrm{Np})$.

Following the retrieval practice phase, the participants were engaged with a mental-rotation distractor task for $5 \mathrm{~min}$. The distractor task was followed by a final retrieval task in which the participants were given a sheet of paper with the names John and Bill at the top and were asked to write down as many traits describing each individual as they could remember. The participants had up to $5 \mathrm{~min}$ to complete the final retrieval task, at the end of which they were debriefed about the purpose of the experiment.

\section{Results and Discussion}

The retrieval practice success rates (defined as the proportion of items correctly recalled during the retrieval practice session) were $83 \%$ for the serial position practice condition, $78 \%$ for the every-other-word practice condition, and $82 \%$ for the random practice condition. A one-way ANOVA demonstrated that there was no difference in retrieval practice success across the three groups $[F(2,46)<$ 
1], indicating that our retrieval practice manipulation did not affect retrieval practice success. Mean proportions of correct recall for $\mathrm{Rp}+, \mathrm{Rp}-$, and $\mathrm{Np}$ items as a function of practice condition are presented in Table 1.

Serial position practice condition. To determine whether there was a difference in the proportion of items recalled as a function of item type, a one-way ANOVA was performed on the proportion of correct recall for each item type $(\mathrm{Rp}+, \mathrm{Rp}-$, and $\mathrm{Np})$. There was a significant difference in proportion of items recalled $[F(2,46)=$ $\left.23.75, M S_{\mathrm{e}}=.04, p<.001\right]$. Paired-samples $t$ tests demonstrated that $\mathrm{Rp}+$ items were significantly better recalled than both Rp - items $[t(23)=6.05, p<.001]$ and $\mathrm{Np}$ items $[t(23)=5.75, p<.001]$, as one would expect from previous research. Critically, however, no retrievalinduced forgetting effect was observed, because there was no difference in recall between $\mathrm{Rp}-$ and $\mathrm{Np}$ items $[t(23)=0.31, p=.76]$. If anything, participants recalled a slightly higher proportion of $\mathrm{Rp}-$ items relative to $\mathrm{Np}$ items. This finding is inconsistent with the inhibitory explanation for retrieval-induced forgetting, because practicing any subset of items should have led to a retrievalinduced forgetting effect.

Every-other-word practice condition. To determine whether there was a difference in the proportion of items recalled as a function of item type, a one-way ANOVA was performed on the proportion of correct recall for each item type $(\mathrm{Rp}+, \mathrm{Rp}-$, and $\mathrm{Np})$. There was a significant difference in proportion of items recalled $[F(2,46)=$ 5.62, $\left.M S_{\mathrm{e}}=.05, p<.01\right]$. Paired-samples $t$ tests demonstrated that $\mathrm{Rp}+$ items were significantly better recalled than both $\mathrm{Rp}-$ items $[t(23)=2.03, p<.05]$ and $\mathrm{Np}$ items $[t(23)=3.28, p<.01]$. As in the serial position practice condition, however, no retrieval-induced forgetting effect was observed, since there was no difference in recall between $\mathrm{Rp}-$ and $\mathrm{Np}$ items $[t(23)=1.30, p=$ $.21]$. Replicating the trend observed in the serial position practice condition, participants recalled a higher proportion of Rp - items than $\mathrm{Np}$ items. Again, this finding is inconsistent with the inhibitory explanation for retrievalinduced forgetting, because practicing any subset of items should have led to a retrieval-induced forgetting effect.

Random practice condition. To determine whether there was a difference in the proportion of items recalled

Table 1

Experiment 1: Mean Proportions (P) of Correct Recall for Rp+ (Practiced Items), Rp - (Unpracticed Items From the Practiced List), and Np (Unpracticed Items From the Unpracticed List) and Standard Deviations (SDs) as a Function of Practice Condition

\begin{tabular}{|c|c|c|c|c|c|c|}
\hline \multirow[b]{3}{*}{ Word Type } & \multicolumn{6}{|c|}{ Practice Condition } \\
\hline & \multicolumn{2}{|c|}{$\begin{array}{c}\text { Serial } \\
\text { Position }\end{array}$} & \multicolumn{2}{|c|}{$\begin{array}{l}\text { Every } \\
\text { Other } \\
\text { Word }\end{array}$} & \multicolumn{2}{|c|}{ Random } \\
\hline & $\mathrm{P}$ & $\overline{S D}$ & $\mathrm{P}$ & $\overline{S D}$ & $\mathrm{P}$ & $\overline{S D}$ \\
\hline $\mathrm{Rp}+$ & .71 & .21 & .58 & .29 & .71 & .23 \\
\hline $\mathrm{Rp}-$ & .39 & .19 & .45 & .27 & .23 & .20 \\
\hline $\mathrm{Np}$ & .37 & .18 & .37 & .22 & .33 & .14 \\
\hline
\end{tabular}

as a function of item type, a one-way ANOVA was performed on the proportion of correct recall for each item type $(\mathrm{Rp}+, \mathrm{Rp}-$, and $\mathrm{Np})$. There was a significant difference in proportion of items recalled $[F(2,46)=42.26$, $\left.M S_{\mathrm{e}}=.04, p<.001\right]$. Paired-samples $t$ tests demonstrated that $\mathrm{Rp}+$ items were significantly better recalled than both $\mathrm{Rp}-$ items $[t(23)=6.05, p<.001]$ and $\mathrm{Np}$ items, $[t(23)=5.75, p<.001]$. Contrary to the findings for the other two practice conditions, a significant retrieval-induced forgetting effect was observed $[t(23)=$ $-2.06, p<.05]$, with participants recalling significantly more Np items than Rp- items. Thus, although we replicated M. D. MacLeod and Macrae's (2001) findings with our random practice condition, we failed to observe retrieval-induced forgetting in our other two retrieval practice conditions.

To ensure that our results in the random practice condition were actually due to retrieval-induced forgetting, we needed to rule out an alternate account - namely, that the decrement for $\mathrm{Rp}-$ items at final recall may have been attributable to output interference. Specifically, participants may have recalled the $\mathrm{Rp}+$ items first because of their greater accessibility, and this may have interfered with their ability to recall Rp - items (see, e.g., Roediger $\&$ Schmidt, 1980). To determine whether or not output interference influenced our results, we used a classification procedure similar to that used by M. D. MacLeod and Macrae (2001; see also Macrae \& MacLeod, 1999). Participants were divided up based on the likelihood that they recalled $\mathrm{Rp}+$ items early in the recall test as opposed to late in the recall test. Critically, there was no difference in the size of the retrieval-induced forgetting effect for the early $\mathrm{Rp}+$ group when compared to the late $\mathrm{Rp}+$ group $[t(11)=-0.17, p=.87]$. Hence, our results cannot be accounted for in terms of output interference.

The present results are inconsistent with an inhibitory view of retrieval-induced forgetting and, instead, favor a strategy disruption account for the effect. Inhibition theory would predict that practicing any subset of items from a studied list would lead to a decrement in recall for the unpracticed items from the same list when compared with items from another unpracticed list. Here, however, we demonstrate that retrieval-induced forgetting can be eliminated if participants are required to practice recalling a subset of items that is unlikely to disrupt their retrieval strategy (assuming that participants attempted to memorize traits serially), a finding more consistent with the strategy disruption account that is often used to explain part-list cuing effects.

\section{EXPERIMENT 2}

Although the results of Experiment 1 were consistent with a strategy disruption account of retrieval-induced forgetting rather than an inhibitory account, our conclusions rest heavily on the assumption that individuals were attempting to encode (and also recall) items serially. The purpose of Experiment 2 was to test this assumption by explicitly instructing participants to memorize items in the 
order in which they were presented. Thus, Experiment 2 was an exact replication of Experiment 1, with the sole exception being that participants were given specific instruction about how items should be memorized. Given the results of Experiment 1, we hypothesized that retrievalinduced forgetting would be observed only in the random practice condition. Were this the case, it would validate our claim that participants attempted to encode items serially in Experiment 1, and that the lack of a retrieval-induced forgetting effect in the serial position and every-other-item conditions was attributable to the practice session's not disrupting each individual's memory strategy.

\section{Method}

Participants. Seventy-two students from the University of Toronto at Scarborough took part individually in a 30-min session and received bonus course credit for their participation. None of the participants had taken part in the first experiment.

Design and Experimental Control. The experiment had a $3 \times$ 3 mixed design, with item type (Rp+, Rp-, or $\mathrm{Np})$ as the withinsubjects factor and rehearsal group (serial position, every other word, or random) as the between-subjects factor. Of the 72 participants, 24 were randomly assigned to each experimental condition.

Apparatus and Procedure. The apparatus and procedure were identical to those in Experiment 1, with one exception: Prior to the study session, the participants were explicitly asked to memorize the items presented to them in the order in which they appeared. Following the final recall test, the participants were also asked to indicate, on a 5-point scale, the degree to which they followed the instructions to memorize items in the order they were presented, as well as the degree to which they attempted to recall items in the order in which they were presented (which they were not instructed to do).

\section{Results and Discussion}

The retrieval practice success rates (defined as the proportion of items correctly recalled during the retrieval practice session) were $74 \%$ for the serial position practice condition, $77 \%$ for the every-other-word practice condition, and $73 \%$ for the random practice condition. The results of a one-way ANOVA showed that there was no difference in retrieval practice success across the three groups $[F(2,46)<1]$, indicating that our retrieval practice manipulation did not affect retrieval practice success. Mean proportions of correct recall for $\mathrm{Rp}+, \mathrm{Rp}-$, and $\mathrm{Np}$ items as a function of practice condition are presented in Table 2.

Serial position practice condition. To determine whether there was a difference in the proportion of items recalled as a function of item type, a one-way ANOVA was performed on the proportion of correct recall for each item type $(\mathrm{Rp}+, \mathrm{Rp}-$, and $\mathrm{Np})$. There was a significant difference in proportion of items recalled $[F(2,46)=10.38$, $\left.M S_{\mathrm{e}}=.03, p<.001\right]$. Paired-samples $t$ tests demonstrated that $\mathrm{Rp}+$ items were recalled significantly better than $\mathrm{Np}$ items $[t(23)=5.02, p<.001]$, as was to be expected. $\mathrm{Rp}+$ items were also recalled better than Rp - items, though this difference did not reach conventional levels of significance $[t(23)=1.49, p=.08]$. (The failure to reach significance is of little concern, given that [1] there is still a strong trend for $\mathrm{Rp}+$ items to be better recalled than $\mathrm{Rp}-$ items and [2] this is likely attributable to the explicit instruction to memorize items in the order in which they were presented, with the benefit of practicing items offset by the strong primacy effect for unpracticed items, consistent with our claim that strategy disruption may influence retrievalinduced forgetting.) Critically, no retrieval-induced forgetting effect was observed, because there was no difference in recall between $\mathrm{Rp}-$ and Np items $[t(23)=0.31, p=.76]$. As in Experiment 1, participants recalled a higher proportion of $\mathrm{Rp}$ - items when compared with $\mathrm{Np}$ items. This finding is inconsistent with the inhibitory explanation for retrieval-induced forgetting, because practicing any subset of items should have led to a retrieval-induced forgetting effect, but it replicates the pattern of results we observed in this condition in Experiment 1.

Every-other-word practice condition. To determine whether or not there was a difference in the proportion of items recalled as a function of item type, a one-way ANOVA was performed on the proportion of correct recall for each item type (Rp+, Rp-, and Np). There was a significant difference in proportion of items recalled $\left[F(2,46)=12.20, M S_{\mathrm{e}}=.04, p<.001\right]$. Paired-samples $t$ tests demonstrated that $\mathrm{Rp}+$ items were significantly better recalled than both $\mathrm{Rp}-$ items $[t(23)=2.27, p<$ $.05]$ and Np items $[t(23)=4.86, p<.01]$. There was also a significant difference in recall between $\mathrm{Rp}-$ and $\mathrm{Np}$ items $[t(23)=2.92, p<.01]$, though this difference was attributable to participants' recalling significantly more $\mathrm{Rp}$ - than Np items and not to retrieval-induced forgetting (in which we would anticipate participants' recalling more $\mathrm{Np}$ items than Rp-items), replicating the trend observed in Experiment 1. Again, this finding is inconsistent with the inhibitory explanation for retrieval-induced forgetting, because practicing any subset of items should have led to a retrieval-induced forgetting effect, but it is consistent with the pattern of results we observed in Experiment 1.

Random practice condition. To determine whether or not there was a difference in the proportion of items recalled as a function of item type, a one-way ANOVA was performed on the proportion of correct recall for each item type $(\mathrm{Rp}+, \mathrm{Rp}-$, and $\mathrm{Np})$. There was a significant difference in proportion of items recalled $[F(2,46)=$ $\left.41.31, M S_{\mathrm{e}}=.03, p<.001\right]$. Paired-samples $t$ tests demonstrated that $\mathrm{Rp}+$ items were significantly better re-

Table 2

Experiment 2: Mean Proportions (P) of Correct Recall for Rp+ (Practiced Items), Rp- (Unpracticed Items From the Practiced List), and Np (Unpracticed Items From the Unpracticed List) and Standard Deviations (SDs) as a Function of Practice Condition

\begin{tabular}{|c|c|c|c|c|c|c|}
\hline \multirow[b]{3}{*}{ Word Type } & \multicolumn{6}{|c|}{ Practice Condition } \\
\hline & \multicolumn{2}{|c|}{$\begin{array}{c}\text { Serial } \\
\text { Position }\end{array}$} & \multicolumn{2}{|c|}{$\begin{array}{l}\text { Every } \\
\text { Other } \\
\text { Word }\end{array}$} & \multicolumn{2}{|c|}{ Random } \\
\hline & $\mathrm{P}$ & $S D$ & $\mathrm{P}$ & $\overline{S D}$ & $\mathrm{P}$ & $S D$ \\
\hline $\mathrm{Rp}+$ & .53 & .30 & .59 & .29 & .71 & .24 \\
\hline $\mathrm{Rp}-$ & .43 & .17 & .43 & .30 & .28 & .16 \\
\hline $\mathrm{Np}$ & .29 & .16 & .29 & .18 & .33 & .13 \\
\hline
\end{tabular}


called than both $\mathrm{Rp}-$ items $[t(23)=6.97, p<.001]$ and $\mathrm{Np}$ items $[t(23)=7.58, p<.001]$. In contrast to the findings for the other two practice conditions, a significant retrieval-induced forgetting effect was observed $[t(23)=$ $-1.98, p<.05$ ], with participants recalling significantly more Np items than Rp-items.

To ensure that our results in the random practice condition were actually due to retrieval-induced forgetting and not output interference, we divided up participants based on the likelihood that they recalled $\mathrm{Rp}+$ items early in the recall test as opposed to late in the recall test. Critically, there was no difference in the size of the retrieval-induced forgetting effect for the early Rp+ group when compared with the late $\mathrm{Rp}+$ group $[t(11)=-1.27, p=.23]$. Hence, our results cannot be accounted for in terms of output interference.

Did participants memorize and recall items in the order in which they were studied? Following the final recall test, participants were asked to rate, on a 5-point scale (with 1 indicating that they made no attempt to memorize/ recall items in the order presented and 5 indicating that they made every attempt to do so), the degree to which they (1) attempted to memorize items in the order in which they appeared (as instructed) and (2) attempted to recall items in the order in which they memorized them (which they were not instructed to do, but which would be consistent with our assumption that practicing a random subset of studied items interferes with a serial retrieval strategy). The mean rating in answer to the question of whether participants followed the instruction to memorize the items in the order in which they appeared was 4.04 for the serial position practice condition (with 22 out of 24 participants rating 4 or higher), 4.00 for the everyother-word practice condition (with 15 out of 24 participants rating 4 or higher), and 4.25 for the random practice condition (with 22 out of 24 participants rating 4 or higher), suggesting that participants followed the instructions provided to them. The results of a one-way ANOVA showed that there was no difference in the degree to which participants followed the instruction to memorize serially across the three groups $[F(2,46)<1]$, indicating that participants in each practice condition were equally likely to follow instructions.

With regard to recall, the mean rating in answer to the question of whether participants attempted to recall items in the same order in which the items had been presented was 3.33 for the serial position practice condition (with 14 out of 24 participants rating 4 or higher), 3.25 for the every-other-word practice condition (with 15 out of 24 participants rating 4 or higher), and 3.29 for the random practice condition (with 15 out of 24 participants rating 4 or higher), indicating that participants were quite likely to attempt to recall items in the order in which they were presented, despite no explicit instruction to do so. That individuals attempted to recall items in the order of initial presentation reinforces the notion that there may be a strategy disruption component to retrieval-induced forgetting that can be neutralized as a function of which items individuals are cued to recall during practice. In ac- cordance with this notion, participants in the every-otherword practice and serial position practice conditions who indicated that they had attempted to recall items in the order in which they were studied recalled a higher proportion of $\mathrm{Rp}-$ items (.54 for the every-other-word condition and .49 for the serial position condition) when compared with participants who indicated that they did not attempt to recall items in the order in which they were studied (.24 for the every-other-word condition, .36 for the serial practice condition). This difference was confirmed by a 2 (practice condition) $\times 2$ (likelihood of attempting to recall items in the studied order: high or low) ANOVA, because there was a main effect of attempted recall order $\left[F(1,8)=14.02, M S_{\mathrm{e}}=.02, p<.01\right]$ but no main effect of practice condition and no interaction between attempted recall order and practice condition (both $F \mathrm{~s}<1$ ). Given that the practice items were selected to be consistent with a serial recall strategy, this finding is strongly consistent with the notion of strategy disruption.

The present results replicate those of Experiment 1, because retrieval-induced forgetting was observed only in the random practice condition. This supports our contention from Experiment 1 that participants likely attempted to memorize and recall items in the studied order. That the retrieval-induced forgetting effect can be neutralized when the subset of practiced items is manipulated is inconsistent with an inhibition account but is consistent with there being a strategy disruption component to retrievalinduced forgetting. In Experiment 3, we attempt to extend this finding to a different set of stimuli.

\section{EXPERIMENT 3}

In the first two experiments, we observed strong evidence in favor of a strategy disruption account of retrievalinduced forgetting. Specifically, the retrieval-induced forgetting effect was moderated by which items participants were cued to recall during the practice session. In these experiments, however, the studied items had no preexisting associations. We selected these items because we felt that this would increase the likelihood that participants would attempt to memorize items serially, which, given the results of Experiments 1 and 2, appears to have been the case. Most studies of retrieval-induced forgetting, however, use categories of items with strong preexisting associations (see, e.g., M. C. Anderson et al., 1994), so it is unclear whether the results from the first two experiments are specific to the stimuli that were used. To determine whether the practice manipulation effect from the first two experiments extends to stimuli with preexisting associations, we replicated Experiment 1 in Experiment 3, with more traditional categorical materials. Given the results of the first two experiments, we predicted that retrieval-induced forgetting would be observed only in the random practice condition.

\section{Method}

Participants. Forty students from the University of Toronto at Scarborough took part individually in a 30-min session and received 
bonus course credit for their participation. None of the participants had taken part in the first two experiments.

Design and Experimental Control. The experiment had a $3 \times$ 2 mixed design, with item type $(\mathrm{Rp}+, \mathrm{Rp}-$, or $\mathrm{Np})$ as the withinsubjects factor and rehearsal group (serial position or random) as the between-subjects factor. Given that the serial position and everyother-word conditions elicited nearly identical results in the first two experiments, we omitted the every-other-word condition from this experiment. Of the 40 participants, 20 were randomly assigned to each experimental condition.

Apparatus and Procedure. The apparatus and procedure were identical to those in Experiment 1, with one exception: Rather than using personality traits, we used experimental stimuli consisting of 24 items, 12 each from two categories (fruits and professions; M. C. Anderson et al., 1994). Each category list was presented in a blocked fashion, and the order of presentation of the items within each list was completely randomized.

\section{Results and Discussion}

The retrieval practice success rates (defined as the proportion of items correctly recalled during the retrieval practice session) were $93 \%$ for the serial position practice condition and $96 \%$ for the random practice condition. A paired-samples $t$ test demonstrated that there was no difference in retrieval practice success between the two groups $[t(19)=0.525, p=.61]$, indicating that our retrieval practice manipulation did not affect retrieval practice success. Mean proportions of correct recall for Rp+, $\mathrm{Rp}-$, and $\mathrm{Np}$ items as a function of practice condition are presented in Table 3.

Serial position practice condition. To determine whether or not there was a difference in the proportion of items recalled as a function of item type, a one-way ANOVA was performed on the proportion of correct recall for each item type (Rp+, Rp-, and $\mathrm{Np})$. There was a significant difference in proportion of items recalled $\left[F(2,38)=9.63, M S_{\mathrm{e}}=.03, p<.001\right]$. Paired-samples $t$ tests demonstrated that $\mathrm{Rp}+$ items were significantly better recalled than both $\mathrm{Rp}-$ items $[t(19)=2.99, p<$ $.01]$ and Np items $[t(19)=4.71, p<.001]$, as one would have expected. As in our first two experiments, no retrievalinduced forgetting effect was observed, because there was no difference in recall between $\mathrm{Rp}-$ and $\mathrm{Np}$ items $[t(19)=0.86, p=.40]$. Participants recalled a slightly higher proportion of $\mathrm{Rp}-$ items when compared with $\mathrm{Np}$ items. This finding replicates our pattern of results from Experiments 1 and 2.

Table 3

Experiment 3: Mean Proportions (P) of Correct Recall for Rp+ (Practiced Items), Rp- (Unpracticed Items From the Practiced List), and Np (Unpracticed Items From the Unpracticed List) and Standard Deviations (SDs) as a Function of Practice Condition

\begin{tabular}{cccccc}
\hline & \multicolumn{3}{c}{ Practice Condition } \\
\cline { 2 - 5 } & \multicolumn{2}{c}{$\begin{array}{c}\text { Serial } \\
\text { Position }\end{array}$} & & \multicolumn{2}{c}{ Random } \\
\cline { 2 - 5 } \cline { 5 - 6 } Word Type & $\mathrm{P}$ & $S D$ & & $\mathrm{P}$ & $S D$ \\
\hline $\mathrm{Rp}+$ & .81 & .17 & & .83 & .17 \\
$\mathrm{Rp}-$ & .62 & .22 & & .54 & .21 \\
$\mathrm{~Np}$ & .58 & .16 & & .65 & .12 \\
\hline
\end{tabular}

Random practice condition. To determine whether there was a difference in the proportion of items recalled as a function of item type, a one-way ANOVA was performed on the proportion of correct recall for each item type (Rp+, Rp-, and Np). There was a significant difference in the proportions of items recalled $[F(2,38)=$ $\left.19.52, M S_{\mathrm{e}}=.02, p<.001\right]$. Paired-samples $t$ tests demonstrated that $\mathrm{Rp}+$ items were significantly better recalled than both $\mathrm{Rp}-$ items $[t(19)=5.10, p<.001]$ and Np items $[t(19)=5.04, p<.001]$. Contrary to the results for the serial position practice condition, a significant retrieval-induced forgetting effect was observed $[t(19)=$ $-2.50, p<.05$ ], with participants recalling significantly more $\mathrm{Np}$ items than $\mathrm{Rp}-$ items. This finding replicates the results of our first two experiments but extends them to a condition in which the studied items had a strong preexisting experimental association.

As in our first two experiments, to ensure that our results in the random practice condition were actually due to retrieval-induced forgetting and not output interference, we divided up participants based on the likelihood that they recalled $\mathrm{Rp}+$ items early as opposed to late in the recall test. There was no difference in the size of the retrievalinduced forgetting effect for the early $\mathrm{Rp}+$ group when compared with the late $\mathrm{Rp}+$ group $[t(9)=-1.17, p=$ .31]. Hence, our results cannot be accounted for in terms of output interference.

\section{GENERAL DISCUSSION}

The present experiments were designed to test whether strategy disruption may play a role in retrieval-induced forgetting effects in much the same way it does for part-list cuing. By manipulating which items were recalled during retrieval practice, we were able to eliminate retrieval-induced forgetting. In our first experiment, retrieval-induced forgetting was observed only in our random practice condition, which is the condition that has most often been used by researchers who have reported these effects. When the retrieval practice session was composed of items that were unlikely to disrupt retrieval strategy, however, retrievalinduced forgetting was neutralized, and participants were more likely to recall $\mathrm{Rp}-$ items when compared with $\mathrm{Np}$ items. This result was also confirmed in our second and third experiments, in which (1) participants were instructed to memorize items in the order in which they were presented (Experiment 2) and (2) participants were given a different set of stimuli (Experiment 3). A strictly inhibitory account would predict that practicing any subset of items from a studied list would lead to an inhibition of the other items from that same list. Thus, the present experiments provide preliminary evidence that strategy disruption can account for certain retrieval-induced forgetting effects. Moreover, our results are consistent with those of Williams and Zacks (2001), who argued that their failure to find differential effects of strong as opposed to weak exemplars on retrieval-induced forgetting is contrary to the inhibition account, and speaks, instead, in favor of a retrieval interference mechanism. Although we recognize 
that retrieval interference is similar to the strategy disruption account outlined here (and our results are also somewhat consistent with the notion of retrieval interference) we have opted to interpret our results in terms of strategy disruption, because Williams and Zacks did not provide any explicit test of retrieval interference. Thus, the present results (1) constitute the first explicit test of the strategy disruption account as it relates to retrieval-induced forgetting and (2) add to a growing literature that suggests that retrieval-induced forgetting may not be accounted for adequately by inhibitory processes.

The present results also have considerable application to the part-list cuing literature. Previously, part-list cuing had been accounted for in terms of inhibition, a claim that has since been disputed by Basden et al. (1977; see also Basden \& Basden, 1995). Basden et al. put forth the original strategy disruption account of part-list cuing, which has endured to the present day. Given the similarity between part-list cuing and retrieval-induced forgetting, we argue that it would be parsimonious if we were able to account for both effects in a similar fashion. The results of all three of our experiments are inconsistent with the inhibitory account of retrieval-induced forgetting but are consistent with a strategy disruption account. If it is the case that both part-list cuing and retrieval-induced forgetting are attributable to similar mechanisms, then it may not be necessary to label them as separate effects. Instead, it could be argued that either retrieval practice or reexposure to a subset of items at retrieval leads to a disruption in retrieval strategy and an overall memory decrement. Clearly, further research will be needed to determine the overlap between these two effects. At the very least, however, the present results provide preliminary evidence that there may be a strategy disruption component to retrievalinduced forgetting that is similar to that observed with part-list cuing.

It is important to note that the results of the present study should not lead to the conclusion that strategy disruption can account for all retrieval-induced forgetting effects. Although we have already outlined how some previously published findings could be perceived as consistent with this view (M. C. Anderson \& McCulloch, 1999; M. D. MacLeod \& Macrae, 2001; R. E. Smith \& Hunt, 2000), it is also the case that a number of interesting findings in the literature do not seem consistent with the notion of strategy disruption. For example, it would be difficult to account for cue-independent forgetting in terms of strategy disruption (M. C. Anderson \& Bell, 2001; M. C. Anderson \& Spellman, 1995). Furthermore, Perfect et al. (2002) have demonstrated that retrieval-induced forgetting effects are observed with implicit tests of conceptual memory (though not for perceptual implicit memory; however, see Veling \& van Knippenberg, 2004), a finding that seems more consistent with inhibitory processes. Retrieval-induced forgetting effects have also been observed on item recognition tests (Hicks \& Starns, 2004), with arbitrary visual objects (Ciranni \& Shimamura, 1999), and with incidental encoding (M. C. Anderson \& Bell, 2001), all situations in which strategy disruption is unlikely to play a role. The purpose of the present work, however, is not to suggest that strategy disruption can account for all retrieval-induced forgetting effects. Rather, the present experiments suggest that there may be a strategy disruption component to the retrieval-induced forgetting effect that has been ignored by researchers to date. Further research will be required to determine whether strategy disruption can account for other important findings in the literature.

Although the present results are the first to demonstrate that retrieval-induced forgetting effects can be neutralized as a function of practice set, this is not the first manipulation that has been shown to reduce or eliminate retrievalinduced forgetting altogether. M. C. Anderson and McCulloch (1999) have demonstrated that item integration can lead to a reduction in, or elimination of, the retrievalinduced forgetting effect, as have R. E. Smith and Hunt (2000), who demonstrated a reduction in the effect when individuals were encouraged to engage in additional "distinctive" processing for each presented word. Although these manipulations have been shown to modulate retrievalinduced forgetting effects, it is unlikely that they played any role in the present study. Given that each experimental condition differed only in the subset of practiced items, there is no reason to think that participants in the serial position and every-other-word practice conditions would attempt to process/memorize items differently than participants in the random practice condition. Nonetheless, future theories of retrieval-induced forgetting will need to take into account which manipulations elicit the effect and which manipulations do not.

In summary, the present experiments tested the inhibitory account of retrieval-induced forgetting. Our results were inconsistent with inhibition theory, however, and were more consistent with strategy disruption theory. With two separate sets of stimuli (with and without preexisting experimental association), we were able to eliminate retrievalinduced forgetting when we cued individuals to recall items during practice that were unlikely to disrupt their retrieval strategy. The present results converge ideally with current theories of both retrieval-induced forgetting and part-list cuing as we attempt to determine whether similar or different processes mediate these effects.

\section{REFERENCES}

Anderson, M. C. (2003). Rethinking interference theory: Executive control and the mechanisms of forgetting. Journal of Memory \& Language, 49, 415-445.

Anderson, M. C., \& Bell, T. (2001). Forgetting our facts: The role of inhibitory processes in the loss of propositional knowledge. Journal of Experimental Psychology: General, 130, 544-570.

Anderson, M. C., BJork, E. L., \& BJork, R. A. (2000). Retrievalinduced forgetting: Evidence for a recall-specific mechanism. Psychonomic Bulletin \& Review, 7, 522-530.

Anderson, M. C., Buork, R. A., \& Buork, E. L. (1994). Remembering can cause forgetting: Retrieval dynamics in long-term memory. Journal of Experimental Psychology: Learning, Memory, \& Cognition, 20, 1063-1087.

Anderson, M. C., Green, C., \& McCulloch, K. C. (2000). Similarity and inhibition in long-term memory: Evidence for a two-factor theory. Journal of Experimental Psychology: Learning, Memory, \& Cognition, 26, 1141-1159. 
Anderson, M. C., \& McCulloch, K. C. (1999). Integration as a general boundary condition on retrieval-induced forgetting. Journal of Experimental Psychology: Learning, Memory, \& Cognition, 25, 608629.

Anderson, M. C., \& Spellman, B. A. (1995). On the status of inhibitory mechanisms in cognition: Memory retrieval as a model case. Psychological Review, 102, 68-100.

ANDERSON, N. H. (1968). Likableness ratings of 555 personality-trait words. Journal of Personality \& Social Psychology, 9, 272-279.

BASDEN, D. R., \& BASDEN, B. H. (1995). Some tests of the strategy disruption interpretation of part-list cuing inhibition. Journal of Experimental Psychology: Learning, Memory, \& Cognition, 21, 1656-1669.

Basden, D. R., Basden, B. H., \& Galloway, B. C. (1977). Inhibition with part-list cuing: Some tests of the item strength hypothesis. Journal of Experimental Psychology: Human Learning \& Memory, 3, 100-108.

BäUML, K.-H. (1998). Strong items get suppressed, weak items do not: The role of item strength in output interference. Psychonomic Bulletin \& Review, 5, 459-463.

Blaxton, T. A., \& Neely, J. H. (1983). Inhibition from semantically related primes: Evidence of a category-specific inhibition. Memory \& Cognition, 11, 500-510

Ciranni, M. A., \& Shimamura, A. P. (1999). Retrieval-induced forgetting in episodic memory. Journal of Experimental Psychology: Learning, Memory, \& Cognition, 25, 1403-1414.

FrANCIS, W. N., \& KučERA, H. (1982). Frequency analysis of English usage: Lexicon and grammar. Boston: Houghton Mifflin.

Hicks, J. L., \& StaRnS, J. J. (2004). Retrieval-induced forgetting occurs in tests of item recognition. Psychonomic Bulletin \& Review, $11,125-130$

Houghton, G., \& TipPer, S. P. (1994). A model of inhibitory mechanisms in selective attention. In D. Dagenbach \& T. H. Carr (Eds.), Inhibitory mechanisms in attention, memory, and language (pp. 53112). San Diego: Academic Press.

MacLeod, C. M., Dodd, M. D., Sheard, E. D., Wilson, D. E., \& BIBI, U. (2003). In opposition to inhibition. In B. H. Ross (Ed.), The psychology of learning and motivation (Vol. 43, pp. 163-214). San Diego: Academic Press.

MacLeod, M. D., \& Macrae, C. N. (2001). Gone but not forgotten: The transient nature of retrieval-induced forgetting. Psychological Science, 12, 148-152.

Macrae, C. N., \& MacLeod, M. D. (1999). On recollections lost: When practice makes imperfect. Journal of Personality \& Social Psychology, 77, 463-473.

PenNey, C. G. (1988). A beneficial effect of part-list cuing with unrelated words. Bulletin of the Psychonomic Society, 26, 297-300.

Perfect, T. J., Moulin, C. J. A., Conway, M. A., \& Perry, E. (2002). Assessing the inhibitory account of retrieval-induced forgetting with implicit-memory tests. Journal of Experimental Psychology: Learning, Memory, \& Cognition, 28, 1111-1119.

PeYniRcioğLU, Z. F. (1989). Part-set cuing effect with word-fragment cuing: Evidence against the strategy disruption and increased-listlength explanations. Journal of Experimental Psychology: Learning, Memory, \& Cognition, 15, 147-152.
Reysen, M. B., \& Nairne, J. S. (2002). Part-set cuing of false memories. Psychonomic Bulletin \& Review, 9, 389-393.

RoEdiger, H. L., III (1974). Inhibiting effects of recall. Memory \& Cognition, 2, 261-269

RoEdiger, H. L., [III], \& SchMidT, S. R. (1980). Output interference in the recall of categorized and paired associate lists. Journal of Experimental Psychology: Human Learning \& Memory, 6, 91-105.

Rundus, D. (1973). Negative effects of using list items as recall cues. Journal of Verbal Learning \& Verbal Behavior, 12, 43-50.

ShaW, J. S., III, BJork, R. A., \& Handal, A. (1995). Retrieval-induced forgetting in an eyewitness-memory paradigm. Psychonomic Bulletin \& Review, 2, 249-253.

Slamecka, N. J. (1968). An examination of trace storage in free recall. Journal of Experimental Psychology, 76, 504-513.

Slamecka, N. J. (1969). Testing for associative storage in multitrial free recall. Journal of Experimental Psychology, 81, 557-560.

Sloman, S. A., Bower, G. H., \& Rohrer, D. (1991). Congruency effects in part-list cuing inhibition. Journal of Experimental Psychology: Learning, Memory, \& Cognition, 17, 974-982.

Sмiтh, A. D. (1971). Output interference and organized recall from long-term memory. Journal of Verbal Learning \& Verbal Behavior, 10, 400-408.

Smith, R. E., \& Hunt, R. R. (2000). The influence of distinctive processing on retrieval-induced forgetting. Memory \& Cognition, 28, 503-508.

Todres, A. K., \& WatKins, M. J. (1981). A part-set cuing effect in recognition memory. Journal of Experimental Psychology: Human Learning \& Memory, 7, 91-99.

Veling, H., \& VAN KNIPPEnberg, A. (2004). Remembering can cause inhibition: Retrieval-induced inhibition as cue independent process. Journal of Experimental Psychology: Learning, Memory, \& Cognition, 30, 315-318.

Williams, C. C., \& ZaCKs, R. T. (2001). Is retrieval-induced forgetting an inhibitory process? American Journal of Psychology, 114, 329-354.

WUNDT, W. (1902). Grundzüge der physiologischen Psychologie (5th ed.). Leipzig: Engelmann.

\section{NOTE}

1. It is important to note that Basden et al. (1977) pit strategy disruption against Rundus's (1973) blocking/retrieval competition model, and it is unclear whether the Rundus model should be thought of as inhibitory. Basden et al. use terminology that suggests that the Rundus model is inhibitory in nature, but it has been argued elsewhere that this model has little to do with inhibition (see M. C. Anderson et al., 1994). Despite the uncertainty, however, the critical point for the present argument is that Basden et al.'s strategy disruption account of part-list cuing has endured as a viable alternative to retrieval competition and inhibition accounts of the effect (both of which are also still favored by some researchers)

(Manuscript received April 22, 2004; revision accepted for publication January 13, 2005.) 